\title{
Herpes simplex esophagitis in immunocompetent hosts
}

\author{
Daniel Eymard MD FRCPC, Luc Martin MD, Gilbert Doummar MD, Jean Piché MD FRCPC
}

\begin{abstract}
D Eymard, L Martin, G Doummar, J Piché. Herpes simplex esophagitis in immunocompetent hosts. Can J Infect Dis $1997 ; 8(6): 351-353$.

Over four months, three cases of biopsy-proven herpes simplex esophagitis were seen at Centre hospitalier PierreBoucher, Longueuil, in young adult males with no evidence of immunosuppression and negative serological testing for antibody against the human immunodeficiency virus. Clinical presentation consisted of odynophagia, fever and retrosternal chest pain. All patients rapidly improved with acyclovir therapy.
\end{abstract}

Key Words: Esophagitis, Herpes simplex virus, Immunocompetent

\section{Esophagite herpétique chez l'hôte immunocompétent}

RÉSUMÉ : Trois jeunes adultes de sexe masculin sans évidence d'immunosuppression ont présenté une esophagite herpétique prouvée à la biopsie. Dans les trois cas, la recherche d'anticorps contre le virus d'immunodéficience humaine s'est avérée négative. La présentation clinique consistait en une odynophagie sévère avec fièvre et douleur rétrosternale. Tous les patients se sont améliorés rapidement avec un traitement à l'acyclovir.

$\mathrm{H}$ erpes simplex virus (HSV) is a double-stranded DNA virus classified into two subtypes: HSV-1 and HSV-2. HSV infections are found worldwide, and the virus has been isolated from nearly all visceral and mucocutaneous sites. Gingivostomatitis and pharyngitis are the most frequent clinical manifestations of first episodes of HSV-1 infection and are most commonly seen in children and young adults (1). The esophagus is the most commonly involved visceral organ in herpes virus infection (2). Herpes simplex esophagitis is usually found in patients with AIDS (3) or malignancies, those receiving immunosuppressive therapy $(4,5)$ and following nasogastric intubation in terminally ill individuals (6). Few papers have described immunocompetent individuals with herpes simplex esophagitis (IHSE) $(7,8)$. We report three cases of IHSE that were seen at the Centre hospitalier PierreBoucher, Longueuil, Québec within four months.

\section{CASE PRESENTATIONS}

Case 1: A 24-year-old man presented to the emergency room with a five-day history of fever, myalgia, headache and odynophagia. His health was previously excellent except for mild asthma, which was controlled by as-needed use of inhaled salbutamol. He had never received corticosteroids and had no known risk factor for human immunodeficiency virus (HIV) infection. He denied prior orolabial herpes infection. Initial evaluation was suggestive of an influenza-like illness, and he was discharged home with no specific therapy. He returned two days later with severe odynophagia and a burning type of retrosternal chest pain. Esophagoscopy revealed plaques of whitish exudate in the mid and distal third plus several 5 to 7 $\mathrm{mm}$ linear erosions distally. Candidiasis was suspected, and oral fluconazole was initiated. However, histological changes in the esophageal biopsies were compatible with herpes infec-

Divisions of Microbiology and Infectious Diseases; and Gastroenterology and Pathology; Centre hospitalier Pierre-Boucher, Longueil, Québec Correspondence and reprints: Dr D Eymard, Centre hospitalier Pierre-Boucher, 1333 Jacques Cartier est, Longueuil, Québec J4M 2 A5.

Telephone 514-468-8111, fax 514-468-8201, e-mail cdochpb@cam.org

Received for publication October 30, 1996. Accepted February 18, 1997 
tion, and HSV-1 was later isolated from these specimens. Ten days after the onset of symptoms, he had persistent odynophagia and nausea, for which rehydration was instituted along with parenteral acyclovir ( $5 \mathrm{mg} / \mathrm{kg}$ every $8 \mathrm{~h}$ ). Symptoms improved over the next $48 \mathrm{~h}$, and oral acyclovir was substituted to complete a total of 14 days of therapy. Total white blood cells (WBC) count was $5.5 \times 10^{9} / \mathrm{L}$, and HIV serology was negative at the time of presentation.

Case 2: A 36-year-old man was admitted with a four-day history of fever, headache, retrosternal and epigastric pain, sore throat and odynophagia. He denied prior orogenital herpes infection, but his new male sexual partner was recently treated for a genital HSV infection. Homosexuality was his only risk factor for HIV infection. Physical examination was significant for a fever of $38.2^{\circ} \mathrm{C}$, bilateral tender cervical adenopathy and multiple pharyngeal ulcers and vesicles from which HSV-1 was cultured. Total WBC count was $5.8 \times 10^{9} / \mathrm{L}$ with CD4 lymphocyte counts of $1.1 \times 10^{6} / \mathrm{L}$, and he had a negative serology for HIV. Endoscopy revealed a single $8 \mathrm{~mm}$ linear erosion at the gastroesophageal junction with typical histological changes of herpetic infection. Intravenous acyclovir was started on the day of presentation with a slow but gradual symptomatic improvement. The patient was switched to oral acyclovir on day 6 to complete a total of two weeks of therapy. One year after this episode, his HIV serology remained negative.

Case 3: A 37-year-old man was evaluated in the emergency room with a two-day history of odynophagia with postprandial, retrosternal burning and epigastric cramps. He had a remote history of two episodes of buccal ulcers and had no known risk factor for HIV infection. Multiple small (less than $5 \mathrm{~mm}$ ) ulcers were seen at endoscopy in the distal esophagus. Results of the biopsies from these lesions were suggestive of herpes infection. Total WBC count was at $7.4 \times 10^{9} / \mathrm{L}$, and HIV serology was negative. Rapid symptomatic improvement occurred with intravenous acyclovir during the first two days followed by oral acyclovir for another 10 days. At one year follow-up, he tested negative for HIV antibodies.

\section{PATHOLOGICAL FINDINGS}

Multiple levels from each of the paraffin blocks were stained with hematoxylin-phloxin-safran and reviewed by two pathologists. The following light microscopy observations were found in all three cases: ulceration with acute inflammation, typical cytopathic epithelial changes with Cowdry type A intranuclear inclusions and ground glass multinucleated giant cells. These findings are compatible with a diagnosis of herpetic esophagitis (6).

\section{DISCUSSION}

HSV esophagitis is considered an opportunistic infection and usually occurs in patients with defects in cell-mediated immunity. The three patients had no clinical evidence of immunosuppression, normal levels of circulating leukocytes and negative serological testing for antibodies against human immunodeficiency virus (HIV-1 and -2). CD4 lymphocyte count was measured in only the second patient and was within normal range.
HSV infection of visceral organs usually results from viremia, and multiple organ involvement is common. However, esophagitis may result from the direct extension of oropharyngeal disease into the esophagus or may occur by reactivation of HSV and spread of the virus to the esophageal mucosa by way of the vagus nerve (1). Patient 2 had active HSV pharyngitis, but esophageal infection was restricted to the distal esophagus. Concommittant oropharyngeal and esophageal disease was present in only five of 31 individuals with IHSE in a recent review by Galbraith and Shafran (9). Patient 3 gave a history suggestive of prior HSV stomatitis, and his esophagitis could have represented a reactivation. The typical clinical presentation of IHSE as previously described (9) is that of a young male with the acute onset of the triad consisting of odynophagia, fever and retrosternal chest pain. Our patients presented in a similar fashion. The fact that the three cases presented over four months suggests that this condition could be under-recognized, given that IHSE is rarely reported.

Although double-contrast esophagography has demonstrated multiple small linear ulcers in patients with IHSE (10), definitive diagnosis must rely on endoscopic biopsy samples for histological examination and virus isolation. Typically, endoscopy reveals erythema and ulcers in the mid and/or distal esophagus, and there may be overlying exudate. Endoscopic findings are nonspecific, and can be confused with candida, cytomegalovirus or peptic esophagitis $(5,9,11)$. HSV-1 was isolated from two of our patients in whom viral culture was attempted. This correlates with the findings of Galbraith and Shafran (9) who reported that all HSV isolated in IHSE were type 1. This predominance of HSV-1 is expected given its greater frequency relative to HSV-2 as the cause of orolabial herpes infection (1).

IHSE is believed to be self-limited and usually resolves over two weeks without specific therapy $(7,9)$. However, spontaneous esophageal perforation complicated by mediastinitis and gastrointestinal bleeding has been reported $(12,13)$. Although no clinical trial has confirmed the efficacy of acyclovir in IHSE, it may prevent complications and accelerate the resolution of symptoms, if started during the symptomatic period of this syndrome.

This report confirms that herpes simplex esophagitis can occur in apparently immunocompetent individuals. Diagnosis is dependent on clinical suspicion, and prompt initiation of antiviral treatment can provide symptomatic relief. Given the frequency of esophagitis in patients with HIV infection it is prudent to rule out coexisting HIV infection.

ACKNOWLEDGEMENTS: The authors thank Dr Mark A Miller for reviewing this manuscript.

\section{REFERENCES}

1. Corey L, Spear PG. Infections with herpes simplex viruses. N Engl J Med 1986;314:749-56.

2. Buss DH, Scharyj MS. Herpesvirus infection of the esophagus and other visceral organs in adults. Am J Med 1979;66:457-62.

3. Bonacini M, Young T, Laine L. The causes of esophageal symptoms in human immunodeficiency virus infection. Arch Intern Med 1991;151:1567-72. 
4. McBane PD, Gross JB. Herpes esophagitis-clinical syndrome, endoscopic appearance and diagnosis in 23 patients. Gastrointest Endosc 1991;37:600-3.

5. Agha FP, Lee HH, Nostrant TT. Herpetic esophagitis: A diagnostic challenge in immunocompromised patients. J Gastroenterol 1986;81:246-52.

6. Nash G, Ross JS. Herpetic esophagitis: A common cause of esophageal ulceration. Hum Pathol 1974;5:339-45.

7. Deshmukh M, Shah R, McCallum RW. Experience with herpes esophagitis in otherwise healthy patients. Am J Gastroenterol 1984;79:173-6.

8. Al-Samman M, Zuckerman MJ, Verghese A, Boman D. Gastric ulcers associated with herpes simplex esophagitis in a nonimmunocompromised patient. J Clin Gastroenterol 1994;18:160.
9. Galbraith JC, Shafran SD. Herpes simplex esophagitis in the immunocompetent patient: Report of four cases and review. Clin Infect Dis 1992;14:894-901.

10. Shortsleeve MJ, Levine MS. Herpes esophagitis in otherwise healthy patients: Clinical and radiographic findings. Radiology 1992;182:859-61.

11. Byard RW, Champion MC, Orizaga M. Variability in the clinical presentation and endoscopic findings of herpetic esophagitis. Endoscopy 1987;19:153-5.

12. Cronstedt JL, Bouchama A, Hainau B, Halim M, Khouqeer F, Darsouny TA. Spontaneous esophageal perforation in herpes simplex esophagitis. Am J Gastroenterol 1992;87:124-7.

13. Ashenbur C, Rothstein FC, Dahms BB. Herpes esophagitis in the immunocompetent child. J Pediatr 1986;108:584-7. 


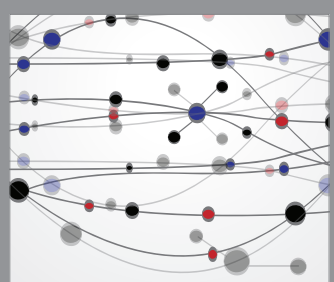

The Scientific World Journal
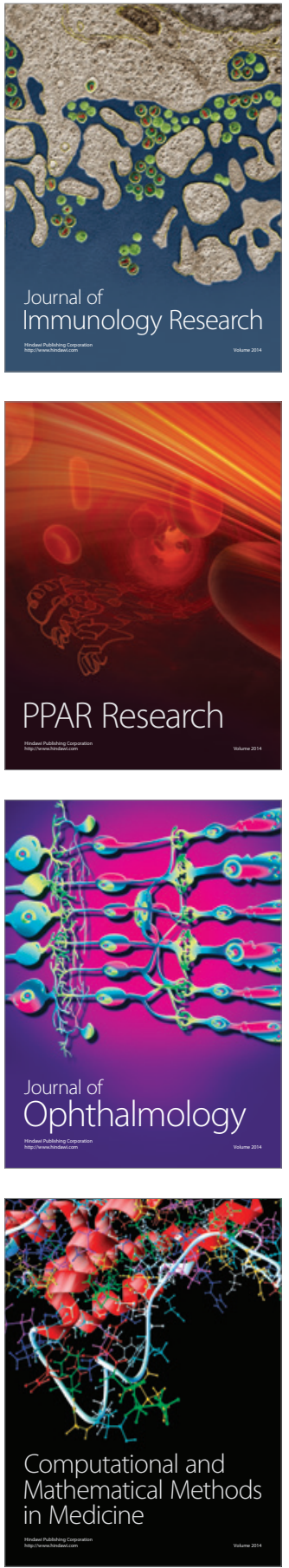

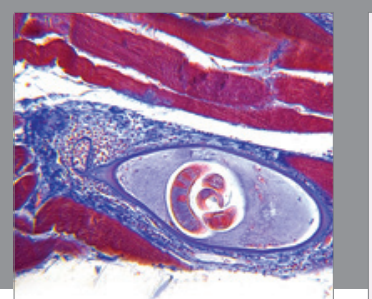

Gastroenterology Research and Practice

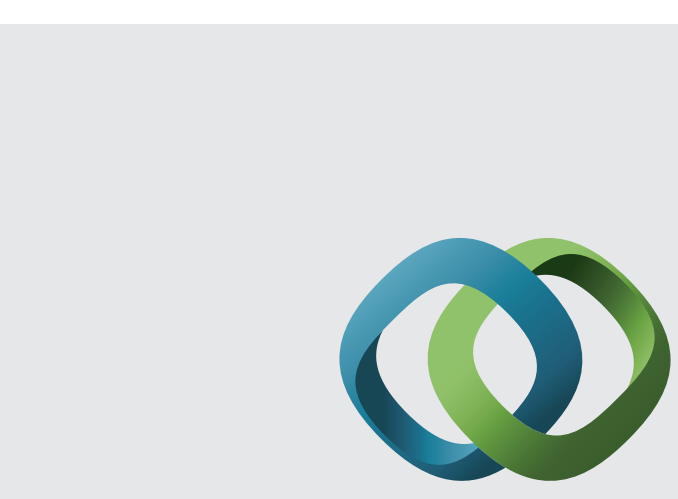

\section{Hindawi}

Submit your manuscripts at

http://www.hindawi.com
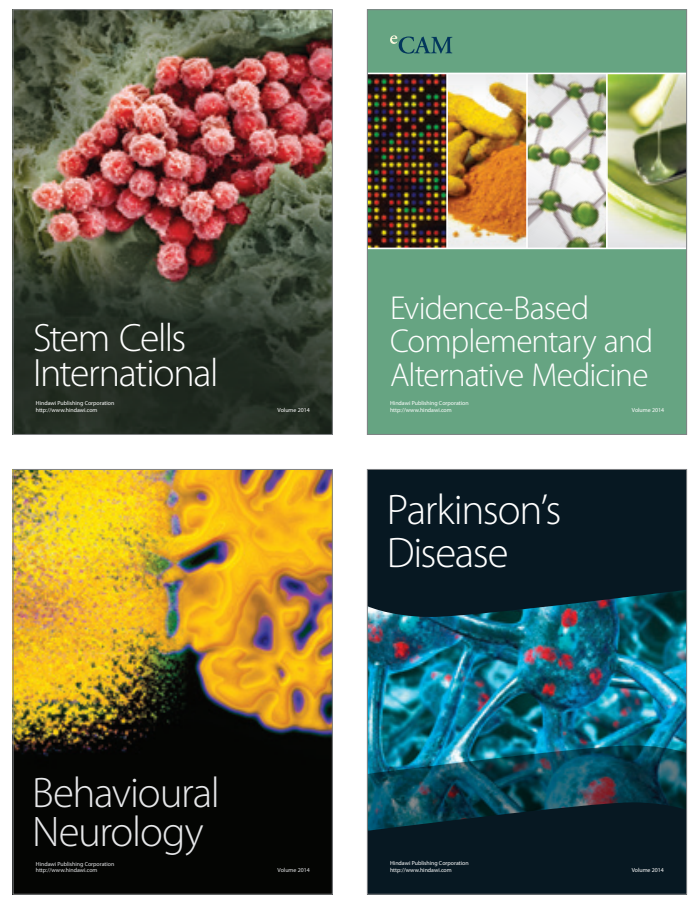
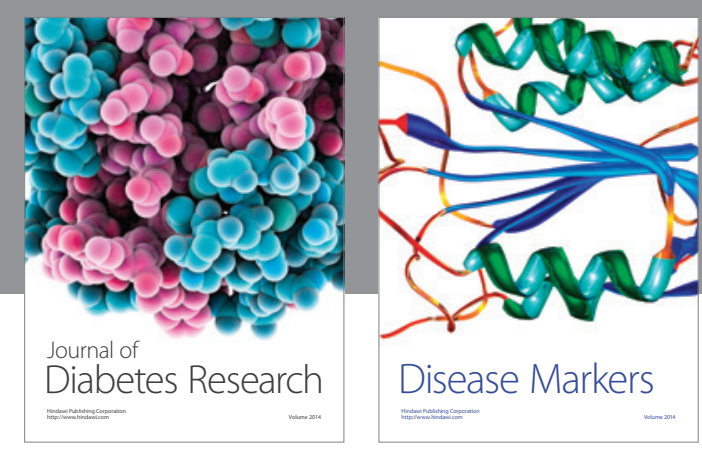

Disease Markers
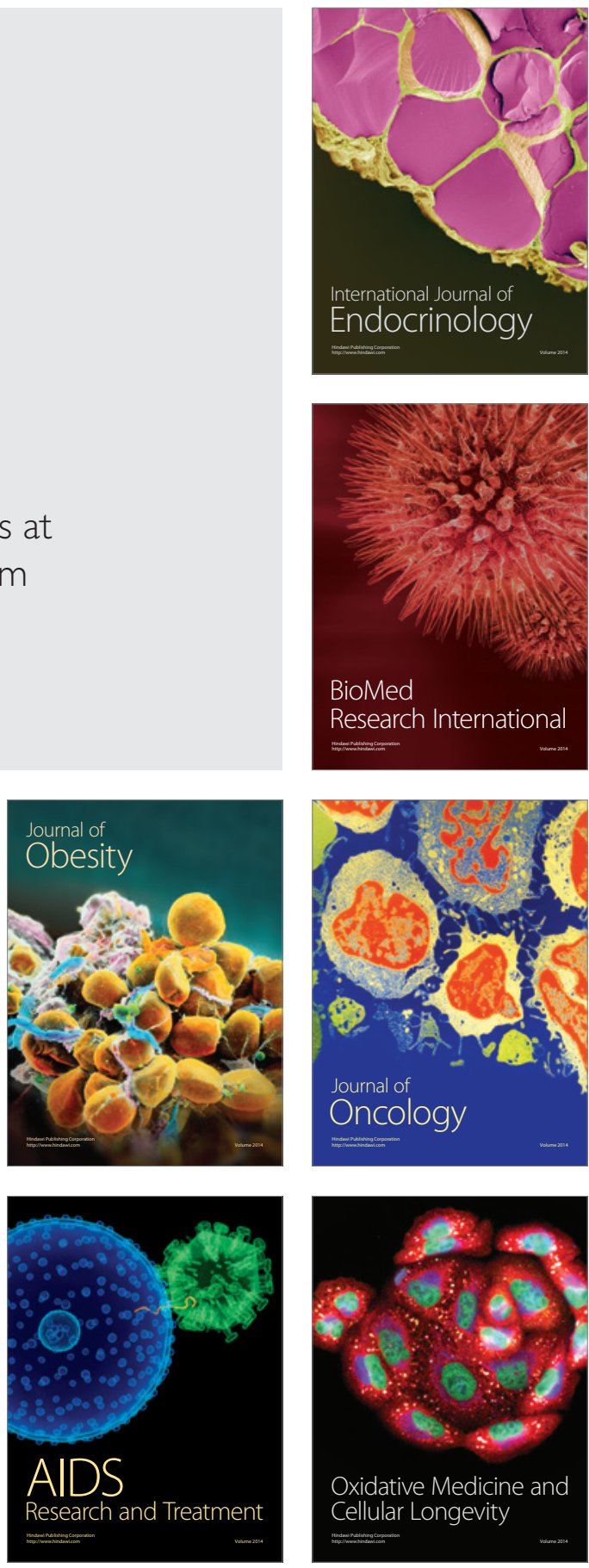